\title{
Design and Implementation of a Low Cost Wireless Ambulatory ECG Monitoring System for Deployment in Rural Communities
}

\author{
https://doi.org/10.3991/ijoe.v15i15.11860 \\ Hassan Ali $\left({ }^{\square}\right)$ \\ The University of Newcastle, Callaghan, Australia \\ hassan.ali@newcastle.edu.au \\ Ben E. Villanueva \\ Rockwell Automation, Corporation Place, Singapore \\ Raziq Yaqub \\ Alabama A\&M University, Alabama, USA
}

\begin{abstract}
Due to the rising number of heart patients and the apparent need for more robust electrocardiogram (ECG) monitoring of these patients, hospitals are increasingly investing in typical cloud technology or centralized hospital server based remote ECG monitoring systems. However, the deployment these systems in rural communities is limited due to the high cost factor. To counter this challenge, in this paper, we focus on the design and implementation of a low cost real time wireless ambulatory ECG monitoring system. The detected ECG signals are first filtered and amplified and then digitally converted by a microcontroller. The digitized ECG signals are then sent over a ZigBee wireless link to a gateway personal computer (PC) at patient's premises. The received ECG data from the ZigBee connection is displayed in real time via the National Instruments (NI) Laboratory Virtual Instrument Engineering Workbench (LabVIEW) user interface on the PC for instant personalized evaluation of the ECG data. The ECG data can be saved on the PC and sent via email to a remote cardiologist or a clinician. Additionally, the gateway PC at patient's end acts as web server for sharing patient's data over the Internet. The remote offsite physician (medical staff in a hospital) can use a web browser on a PC, laptop or a mobile phone with Internet connection to access patient's real time ECG trace for monitoring, expert review and diagnosis. It is shown that the system prototype allows users to acquire reliable ECG signals effectively and simply. The proposed ambulatory ECG system offers an alternative low cost deployment strategy and is especially suited for remote cardiac monitoring of patients in rural communities.
\end{abstract}

Keywords - Electrocardiogram, ambulatory, ZigBee, LabVIEW, web interface 


\section{Introduction}

Cardiovascular diseases (CVDs) are a leading cause of mortality globally. A greater number of individuals perish every year from CVDs than from any other cause. According to the World Health Organization (WHO), an estimated 17.9 million people died from CVDs in 2016, representing $31 \%$ of all global deaths [1]. If the patients with heart abnormalities can be identified, sudden cardiac attacks can be prevented. It is therefore, improving affordability and accessibility of ECG monitoring systems is an important step towards the CVD prevention. Consequently, there has been growing demand for low cost, low power and reduced size ECG systems. Accordingly, many researchers have contributed in the design and development of ECG monitoring systems [2]-[13].

Today, ambulatory ECG monitoring systems play a prominent role in healthcare products. Ambulatory ECG systems generally exploit two to three electrodes to measure and record the ECG signals [14]-[22]. These systems not only facilitate remote monitoring of cardiac activity outside the clinical setting and establish a user cardiologist interface, but also allow continuous monitoring of cardiovascular health, for early detection of fatal risks [5]. In order to make ambulatory ECG systems that are easy to setup, wearable, and tolerant of artifacts, endeavors have been made to develop portable ECG systems. Due to the recent advances in wireless and electronics technologies, these systems replace the conventional wired ECG monitoring system with a wearable ECG device capable of capturing and transmitting ECG data wirelessly to a smartphone [6]-[9], [14], [15], [20]-[22]. The data can be visualized and saved on a smart phone, and then uploaded to a local PC through Bluetooth [10]-[13], or directed to a cloud [23,24] or a centralized hospital subsystem/server [25]-[28].

Cardiovascular diseases in rural communities take a large toll of human lives due to inadequate cardiac facilities and delayed diagnosis. The challenge is to make real time ambulatory ECG monitoring and diagnosis services affordable for deployment in rural communities which are more in need of a qualified remote medical assistance than patients in urban areas. Though the cloud and centralized hospital server based ambulatory ECG monitoring systems have long been recognized as relevant and have been the target of investments by hospitals. However, unfortunately, cloud facilities tend to be commercially driven and thus attract high monthly subscription premiums. Also, hospital based centralized servers (centralized data management system for data storage, analysis and access) involve high costs associated with the infrastructure, software, operation and maintenance, and users' training. This puts significant cost impact on patients as they need to pay increased cost per diagnosis. High cost factor is thus a major hurdle in widespread deployment of cloud and centralized server based remote ECG monitoring systems in rural communities.

Wireless technology ensures patient's freedom of movement while the patient is being monitored. Growing presence of wireless networks also justifies the realization of wearable ECG devices that forward the ECG trace to a nearby communication device. Bluetooth and ZigBee [29-31] are the two main low power wireless transmission technologies used in ECG wireless monitoring systems. ZigBee is an open global standard protocol designed for use with wireless personal area networks (WPANs). 
It is an IEEE 802.15.4 based specification used to create wireless networks that require a low data transfer rate, increased energy efficiency and secure networking [32]. The performance of both the ZigBee and Bluetooth is somewhat similar; however, ZigBee is more commonly used in relaying data for environmental monitoring [33], home automation, industrial automation, security systems and smart lighting applications. ZigBee is also used in elderly people monitoring, which suffer from heart diseases and/or diabetes [34].

Web based access provides simultaneous site access to different clients. Accordingly, several works on web based ECG monitoring systems have been reported in the literature [35]-[37]. In [35], Onder et al. developed a web based wireless ECG measuring and recording system. A system allowing remote ECG monitoring via ARM9 web server technology is presented in [36]. Also, a cloud based web page in [37] allows the patient's physician to analyze real time ECG signals.

Motivated by above developments, and towards our objective of low cost ambulatory ECG monitoring system for patients in rural communities, this paper focuses on the prototype design and implementation of a low cost single channel wireless ECG monitoring system for ambulatory environments. The system allows transmission of captured ECG data through email and sharing of real time data through a web interface to an off-site cardiologist or medical staff in a hospital.

Since the cloud facilities and centralized data servers are still a considerable burden on the diagnosis cost, we consider the use of communication device (mobile phone or a PC) at the patient's end as an alternative solution without incurring any additional cost. However, since it is impractical to implement the server on patients' smart phone due to limited power, data storage, processing and analysing capabilities; computer-based ECG monitoring is becoming an efficient approach for acquisition and analysis of ECG signals. It is for this reason, we use a PC at patient's end to serve as a web server as well as act as a wireless gateway to collect, store and process data from the patient wirelessly. A popular single board computer like the Raspberry Pi [38] can be used for this purpose. However, since PCs are already diffused as Internet gateways (or access points (APs)) in our homes, so possibility of using a Raspberry Pi is discarded to save on prototype development costs.

To increase the battery life, it is decided to use low cost and low power ZigBee wireless technology for to transmit ECG signals from the data acquisition module to the patient's PC. Other factors that also supported ZigBee's usage include secure transmission, good transmission range, flexible network structure, ease of implementation with the commercial off the shelf (COTS) modules for rapid prototype development and potential for mass market deployment advantage in emerging medical wireless sensor networks (WSNs).

LabVIEW [39] is used to establish the ZigBee based gateway PC interface for data visualization at patient's end. Also, LabVIEW is used to establish a web based interface for to share real time ECG information with an off-site cardiologist or medical staff from a hospital.

In Section 2, we provide an overview of the proposed ECG monitoring system. We then follow detailed system design in Section 3, which is then followed by hardware implementation testing in Section 4. NI LabVIEW application program design and 
web interface are presented in Section 5 and 6, respectively. Discussion is presented in Section 7. Finally, the paper is concluded in Section 8 by suggesting some key application of the proposed design and future research directions.

\section{System Description}

Figure 1 shows system architecture of the proposed ECG prototype monitoring system. The system comprises of a data acquisition and transmitting unit, a receiving unit (also called communication device for sharing ECG data over the Internet) at patient's end and a remote web interface.
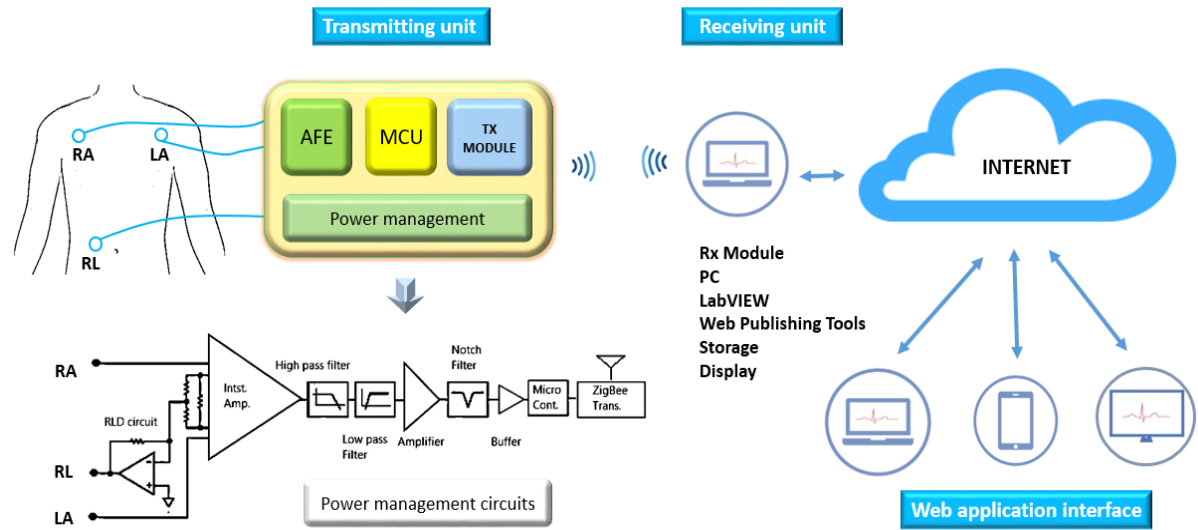

Fig. 1. Proposed ambulatory ECG system architecture.

The transmitter unit's main function is data acquisition and simultaneous wireless data transfer to the receiver unit. The transmitter unit consists of electrodes followed by an analogue frontend (AFE), a microcontroller and a ZigBee transmitter module. The electrical signals are acquired from the patient using three electrodes. Electrodes (RA) and (RL) sense a differential signal through the instrumentation amplifier (INA) (at the first stage of the AFE) and are placed on the patient's upper body. The third electrode is a right leg drive (RLD) connection circuit for to suppress $50 / 60 \mathrm{~Hz}$ surrounding power line noise by driving the body to cancel the interference. The signal is then filtered through a bandpass (BP) filter. A non-inverting amplifier is then used to amplify the signal so that it can occupy the microcontroller's analogue-to-digital converter (ADC) input range. At the final stage of the AFE a notch filter is added to the amplifier signal output to further reject the power line noise. The signal is then fed into the microcontroller via the ADC input. The digitally converted signal is then given to the ZigBee transmitter for onward wireless transmission to the receiver unit.

The receiver unit consists of a ZigBee receiver, a ZigBee explorer dongle [40] and a PC with Internet access. The ZigBee explorer captures the received digital signal from the ZigBee receiver and channels the captured signal to the connected PC for 
display, analysis, and recording through a LabVIEW based user interface for personal evaluation by the user.

To target the remote patient monitoring, the third part of the system is the remote web interface. At patient's end LabVIEW on the PC serves as the web server. This backend server acts as the communication hub. Off site cardiologist and/or medical staff at a remote hospital can access real time data of their patient via this interface.

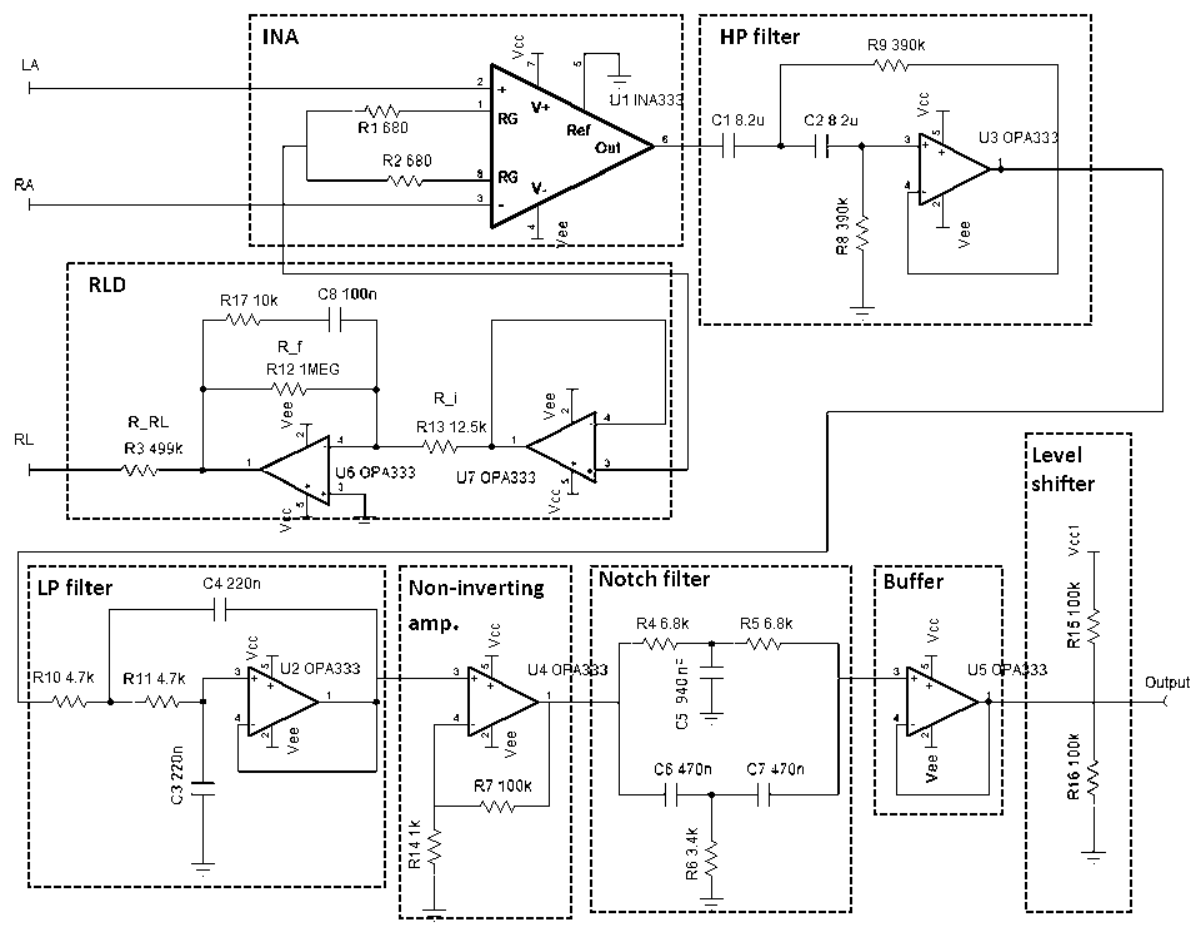

Fig. 2. Proposed AFE circuit.

\section{$3 \quad$ System Design}

\subsection{Electrodes}

In our prototype design, it was decided to use disposable wet silver/silver chloride $(\mathrm{Ag} / \mathrm{AgCl})$ electrodes, due to their low skin-electrode impedance, low noise and low motion artifact, to capture ECG bio-potentials in microvolts $(\mu \mathrm{V})$ range. In these electrodes, a high viscosity electrolytic gel is used to reduce skin-electrode interface impedance and assist the electrochemical reactions. The electrodes were connected to the AFE using ECG lead cables. 


\subsection{AFE}

The AFE effectively removes the noise picked up by the ECG electrodes and amplifies the preserved ECG signal. Figure 2 shows details of the AFE signal chain. The Texas Instruments TI-OPA333 op-amp [41] possesses excellent common mode rejection ratio (CMRR) (up to $130 \mathrm{~dB}$ ), very low offset voltage, low quiescent current, high-impedance inputs, and allows single or dual supplies as low as $1.8 \mathrm{~V}( \pm 0.9 \mathrm{~V})$ and up to $5.5 \mathrm{~V}( \pm 2.75 \mathrm{~V})$. We thus decided to base our AFE design on the OPA333. Design of each AFE block is described next.

Table 1. INA specifications

\begin{tabular}{|l|c|c|c|}
\hline \multicolumn{1}{|c|}{ Model Name } & INA333 [40] & INA128 [41] & INA118 [42] \\
\hline Supply Voltage & \pm 1.8 to $5.5 \mathrm{~V}$ & \pm 4.5 to $36 \mathrm{~V}$ & \pm 2.7 to 36 V \\
\hline CMRR & $100 \mathrm{~dB}$ & $120 \mathrm{~dB}$ & $107 \mathrm{~dB}$ \\
\hline Input Offset & $25 \mu \mathrm{V}$ & $50 \mu \mathrm{V}$ & $50 \mu \mathrm{V}$ \\
\hline Input Bias Current & $5 \mathrm{nA}$ & $5 \mathrm{nA}$ & $0.2 \mathrm{nA}$ \\
\hline Noise & $50 \mathrm{nV} / \sqrt{\mathrm{Hz}}$ & $8 \mathrm{nV} / \sqrt{\mathrm{Hz}}$ & $10 \mathrm{nV} / \sqrt{\mathrm{Hz}}$ \\
\hline Quiescent Current & $0.05 \mathrm{~mA}$ & $0.7 \mathrm{~mA}$ & $0.35 \mathrm{~mA}$ \\
\hline Gain & 1 to 1000 & 1 to 10000 & 1 to 10000 \\
\hline Price $(\sim)$ & $\$ 4.32$ & $\$ 6.32$ & $\$ 10.20$ \\
\hline
\end{tabular}

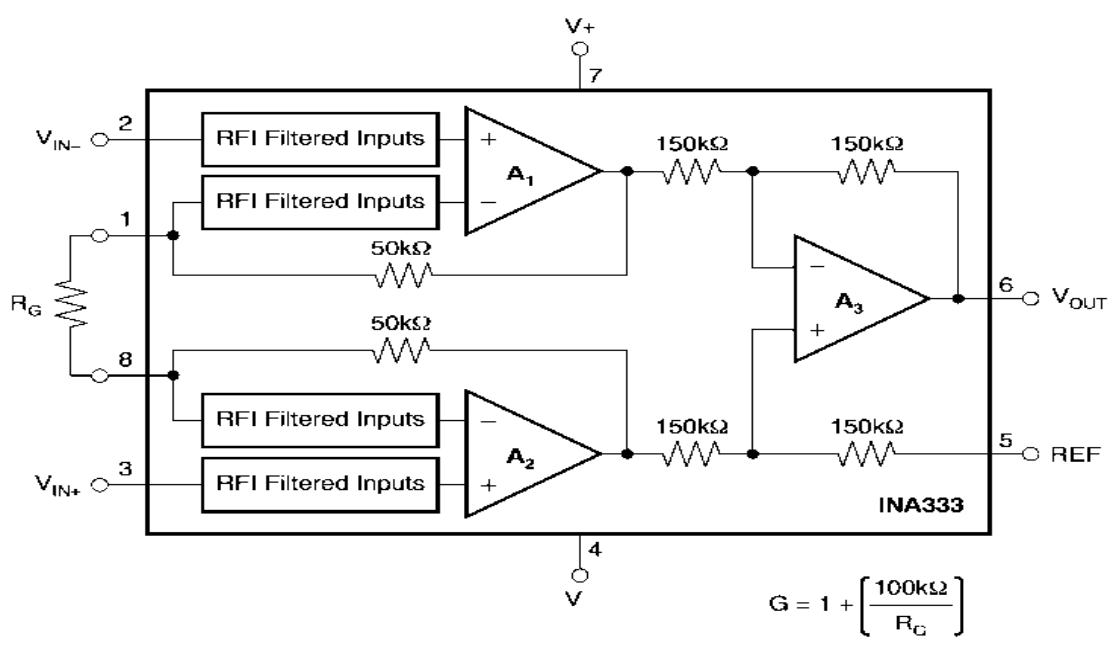

Fig. 3. INA333 basic connections [43].

INA: INAs are usually connected to electrodes with ECG lead wires. These leads are susceptible to noise and can easily pick up $50 / 60 \mathrm{~Hz}$ noise from the nearby power lines as well as much higher frequencies from the surrounding environment. It is therefore important for INAs to possess a high CMRR. Also, an INA must have low power consumption and low input offset voltage. The offset drift of the INA input stage becomes the dominant source of offset error as the gain increases [39]. For our system, we thus aimed at an INA with a CMRR of at least $90 \mathrm{~dB}$, with low power consumption and low offset voltage. Taking these points into consideration, three TI 
INAs: INA333 [43], TI-INA128 [44] and TI-INA118 [45], were shortlisted out of tens of other INAs. Table I contrasts the differences between the three INA characteristics. Since INA333 has the lowest power consumption, input offset voltage, and cost, INA333 was thus selected for the AFE design.

Figure 3 shows INA333's basic connections. The gain of INA33 can be configured by a single external gain resistor $R_{G}$ connected between pins 1 and 8:

$$
G=1+\frac{100 \mathrm{k} \Omega}{R_{G}}
$$

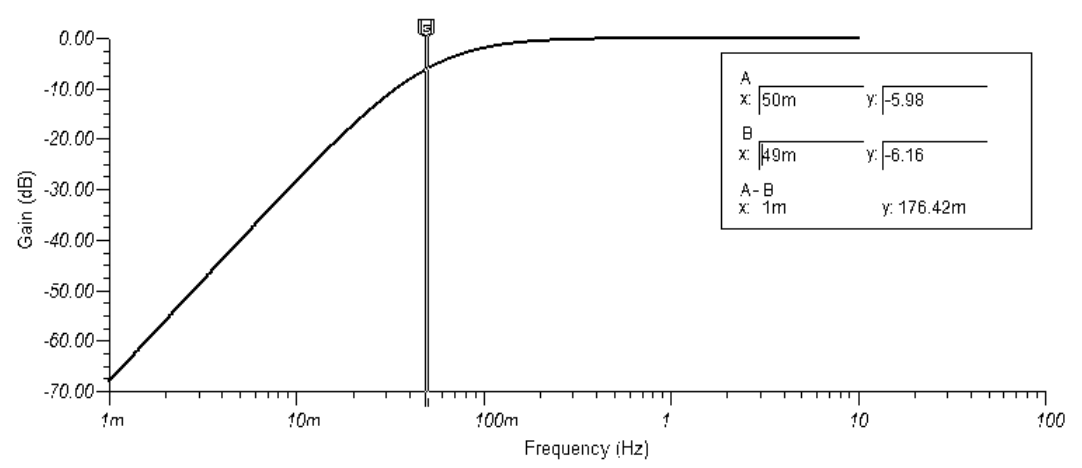

Fig. 4. Second order unity gain Sallen-Key HP filter simulation result.

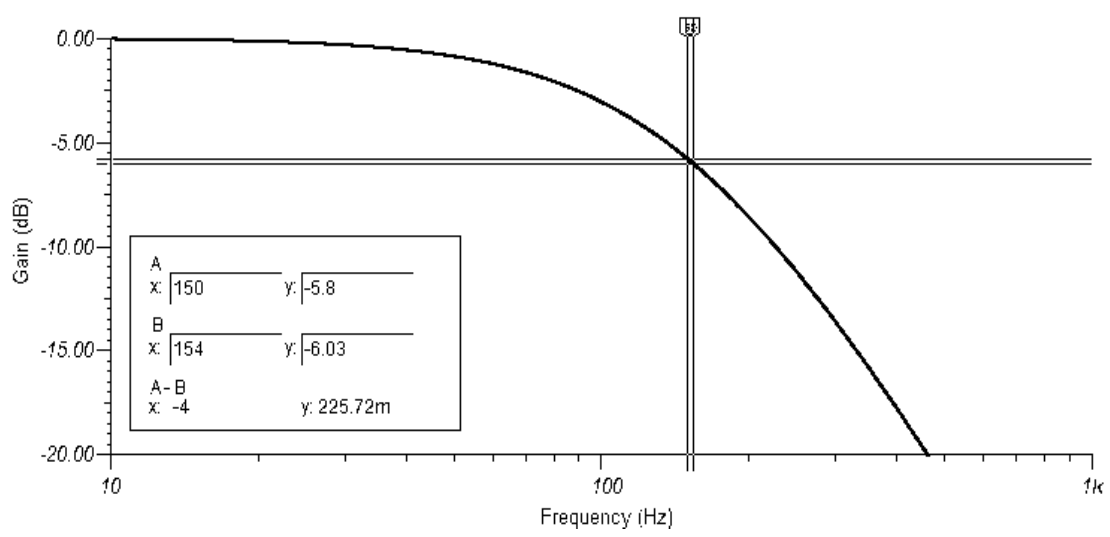

Fig. 5. Second order unity gain Sallen-Key LP filter simulation result.

The INA gain was set to $74.52 \operatorname{using} R_{G}=1360 \Omega$. At this setting, the typical ECG signal amplitude of $5 \mathrm{mV}$ is amplified to $0.3726 \mathrm{~V}$.

BP filter: The INA output is connected to the BP filter. Different scientific societies recommend the ECG signal bandwidth of $0.05-150 \mathrm{~Hz}$ [46]. In our work, we have taken reference to these guidelines to set cut off points of the BP filter. The second order Sallen-Key high pass and low pass filter configurations only need a single opamp. These configurations are therefore easier to implement and generally cheaper. It 
is for this reason; the BP filter was built through a cascade of a second order SallenKey HP filter and a second order Sallen-Key LP filter.

The second order unity gain Sallen-Key HP filter topology $\left(R_{8}, R_{9}, C_{1}, C_{2}\right.$ and $\left.U_{3}\right)$ is shown in Figure 2. The filter frequency response is given by

$$
H(j \omega)=\frac{(j \omega)^{2}}{(j \omega)^{2}+\frac{\omega_{n}}{Q} j \omega+\omega_{n}^{2}}
$$

where the cut off frequency $\omega_{n}=\frac{1}{\sqrt{R_{8} R_{9} C_{1} C_{2}}}$ and the $Q$ factor $Q=\frac{\sqrt{R_{8} R_{9} C_{1} C_{2}}}{\left(C_{1}+C_{2}\right) R_{9}}$.

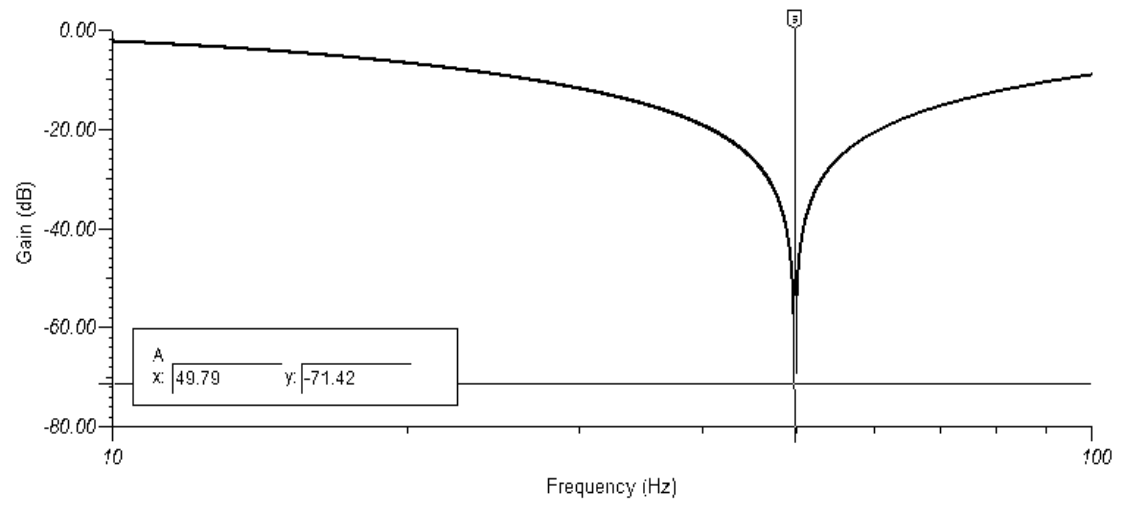

Fig. 6. Twin T-notch filter simulation result.

For this topology, a cut off frequency $0.05 \mathrm{~Hz}$ was targeted. We chose $R_{8}=R_{9}=390 \mathrm{k} \Omega$ and $C_{1}=C_{2}=8.2 \mu \mathrm{F}$ to set the cut off frequency at $0.049 \mathrm{~Hz}$ and the $Q=0.5$. The HP filter simulation result in Figure 4 shows a target frequency of $0.05 \mathrm{~Hz}$ attenuated at $-5.98 \mathrm{~dB}$. In contrast, the estimated (calculated from $R$ and $C$ component values) cut-off frequency of $0.049 \mathrm{~Hz}$ is attenuated at $-6.16 \mathrm{~dB}$.

Figure 2 shows the second order unity gain Sallen-Key LP filter topology $\left(R_{10}, R_{11}, C_{4}, C_{3}\right.$, and $\left.U_{2}\right)$. The filter frequency response is given by

$$
H(j \omega)=\frac{\omega_{n}}{(j \omega)^{2}+\frac{\omega_{n}}{Q} j \omega+\omega_{n}^{2}}
$$

where the cut off frequency $\omega_{n}=\frac{1}{\sqrt{R_{10} R_{11} C_{3} C_{4}}}$ and the $Q$ factor $Q=\frac{\sqrt{R_{10} R_{11} C_{3} C_{4}}}{\left(R_{10}+R_{11}\right) C_{3}}$.

For this configuration, a cut off frequency of $150 \mathrm{~Hz}$ was targeted. We chose $R_{10}=R_{11}=4.7 \mathrm{k} \Omega$ and $C_{3}=C_{4}=0.22 \mu \mathrm{F}$ to achieve an estimated frequency of $154 \mathrm{~Hz}$ and $Q=0.5$. Corresponding simulation results in Figure 5 shows the target frequency of $150 \mathrm{~Hz}$ attenuated at $-5.98 \mathrm{~dB}$, whereas, the estimated frequency of 154 $\mathrm{Hz}$ is attenuated at $-6.03 \mathrm{~dB}$.

Non-inverting op-amp: Between the LP filter and the notch filter in Figure 2, a non-inverting amplifier $\left(R_{7}, R_{14}\right.$, and $\left.U_{4}\right)$ was employed to adjust the signal for the 
microcontroller's ADC input range. The closed loop gain of the resulting amplifier $A_{v}=1+\left(R_{7} / R_{14}\right)$ was set to provide a gain of 11 . This makes total AFE gain of around 819.72 , amplifying typical $5 \mathrm{mV}$ ECG signal to $4.09 \mathrm{~V}$.

Notch filter: A Twin-T notch filter $\left(R_{4}, R_{5}, R_{6}, C_{5}, C_{6}\right.$, and $\left.C_{7}\right)$ shown in Figure 2 was used to suppress $50 \mathrm{~Hz}$ noise. The filter is composed of two T-networks:

- The RCR network is formed by two resistors $R_{4}=R_{5}=R$ and one capacitor $C_{5}=2 C$.

- The CRC network is formed by two capacitors $C_{6}=C_{7}=C$ and one resistor $R_{6}=R / 2$.

The filter's frequency response is given by

$$
H(j \omega)=\frac{(j \omega)^{2}+\omega_{n}^{2}}{(j \omega)^{2}+\frac{\omega_{n} j \omega}{Q}+\omega_{n}^{2}}
$$

where the cut off frequency $\omega_{n}=1 / R C$ and $Q=0.25$. Using the closest resistor and capacitor values $(R=6.8 \mathrm{k} \Omega$ and $C=470 \mathrm{nF})$ the notch filter simulation results are shown in Figure 6. Notice that the T-notch filter has a soft cut-off and desired notch frequency is attenuated at $-71 \mathrm{~dB}$.

Voltage follower: Following the notch filter, a voltage follower is constructed using a non-inverting op-amp. The voltage follower provides very high input impedance to the source circuit and very low output impedance to the load circuit. It thus behaves like a perfect voltage source for the microcontroller without any overloading effects to the AFE circuit.

Right leg driver (RLD) circuit: The RLD circuit has been used in many ECG acquisition systems [44, 45]. The main purpose of the RLD is to invert and amplify the common mode signal (in the powerline interference), and then feeding the signal back into the patient's right leg. The circuit thus cancels the $50 / 60 \mathrm{~Hz}$ noise and creates a cleaner ECG output signal. In the Figure 2 RLD circuit, two op-amps $U_{6}$ and $U_{7}$ are used. The first acts as a buffer with unity gain and infinite passband range, and the second acts as an inverting amplifier.

For the RLD circuit in Figure 2, the common mode voltage

$$
v_{c m}=\frac{R_{R L}}{1+R_{f} / R_{i}} i_{d}=\frac{R_{3}}{1+R_{12} / R_{13}} i_{d}
$$

where $i_{d}$ is the body's displacement current due to the op-amp output. It can be easily observed from (5) that by increasing the gain of the amplifier (large $R_{f}$ and small $\left.R_{i}\right), v_{c m}$ can be decreased.

A larger gain improves the CMRR, giving better signal, but it is limited by the offset of the electrode, amplifier and supply rail. Also, stability problems are encoun- 
tered with the cable impedance. To balance this, the bandwidth of the op-amp is decreased, as we increase the gain.

The inverting amplifier has a voltage gain of $A=\frac{R_{f}}{R_{i}}=\frac{R_{12}}{R_{13}}=\frac{1 \mathrm{M} \Omega}{12.5} \mathrm{k} \Omega=80$ and a low-pass cut-off frequency of $f_{3 d B}=\frac{1}{2 \pi R_{17} C_{8}}=\frac{1}{2 \pi \times 10 \mathrm{k} \Omega \times 0.1 \mu \mathrm{F}}=159.15 \mathrm{~Hz}$ for stability. Also, a resistance $R_{R L}=499 \mathrm{k} \Omega$ at the RLD output is used to limit the current driven to the patient's body.

\subsection{ATmega328P microcontroller}

ATmega328P [49] is a $16 \mathrm{MHz}$, high performance, low power 8-bit microcontroller based on the reduced instruction set computer (RISC) architecture. It features 32 $\mathrm{KB}$ of flash memory, 14 digital input output (I/O) pins, 6 analogue I/O pins, and operates between 1.8-5.5 volts. The ATmega328P was used to convert AFE output signal to the digital domain using its ADC. The ATmega328P ADC has a 10-bit resolution, which translates input voltages from 0 to $5 \mathrm{~V}$ into integer values from 0 to 1023 , yielding a resolution of $4.9 \mathrm{mV}$ per unit.

Figure 7 shows the corresponding oscillator circuit for the $16 \mathrm{MHz}$ clock and the AFE output signal connection to the ATmega328P ADC pin A0. For 10-bit accuracy, the ATmega328P ADC clock needs to be between $50 \mathrm{kHz}$ and $200 \mathrm{kHz}$. ATmega328P uses a $16 \mathrm{MHz}$ clock, 128 pre-scaler factor setting was therefore used to get the ADC clock rate of $125 \mathrm{kHz}$.

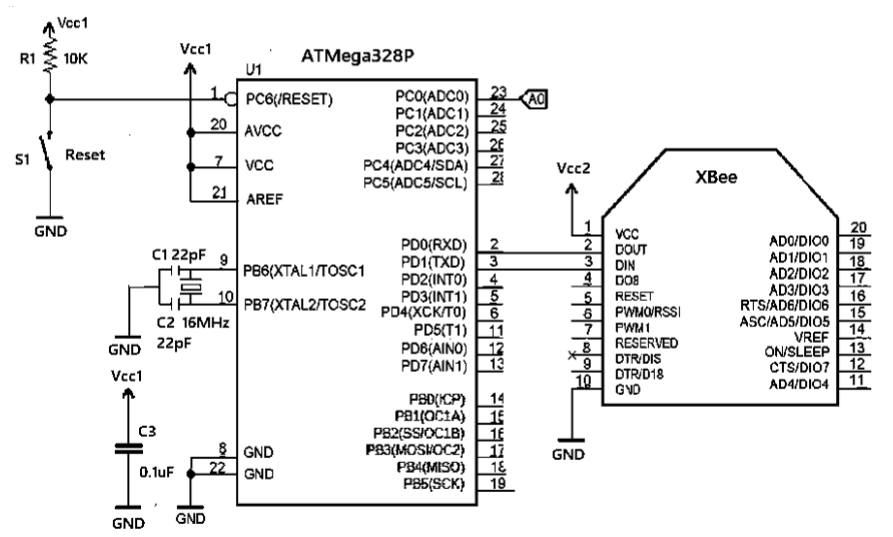

Fig. 7. AFE input to the ATmega328P ADC input, $16 \mathrm{MHz}$ oscillator circuit, and connection to the XBee transmitter.

According to the Nyquist-Shannon sampling theorem, when digitizing an analogue signal, the sampling rate must be at least two times higher than its maximum frequency to avoid aliasing problem. Theoretically, sampling rate of $300 \mathrm{~Hz}$ was enough for ECG to satisfy this requirement (as we were interested in frequencies of upto $150 \mathrm{~Hz}$ ). However, to track the input signal more accurately, the ADC sampling rate was set at $1 \mathrm{kHz}$. 


\subsection{ZigBee wireless communication}

XBee radio family consists of various XBee radio frequency (RF) modules with different specifications [50]. XBee modules support ZigBee protocol and generally, operate within the industrial, scientific and medical (ISM) $2.4 \mathrm{GHz}$ (Unlicensed) frequency band. To be more specific, XBee Series I transceivers [51] were selected due to their low power consumption, low cost, small size and modularity advantages. An XBee adapter board [52] was utilized to connect XBee with the microcontroller at the transmitting end. The microcontroller uses a universal asynchronous receiver/transmitter (UART) port for communication with the XBee module. Figure 7 shows the corresponding microcontroller connections to the XBee transmitter. At the receiver end, receiving XBee was interfaced with a $\mathrm{PC}$ using the XBee explorer dongle.

Using XCTU software [53], one XBee was configured in the transparent mode (AT) as a transmitter while the other XBee attached to the PC was configured as a receiver in AT mode. Also, channel, personal area network identifier (PAN ID), destination address high (DAH), destination address low (DAL) and 16-bit source address were configured for secure point to point communication.

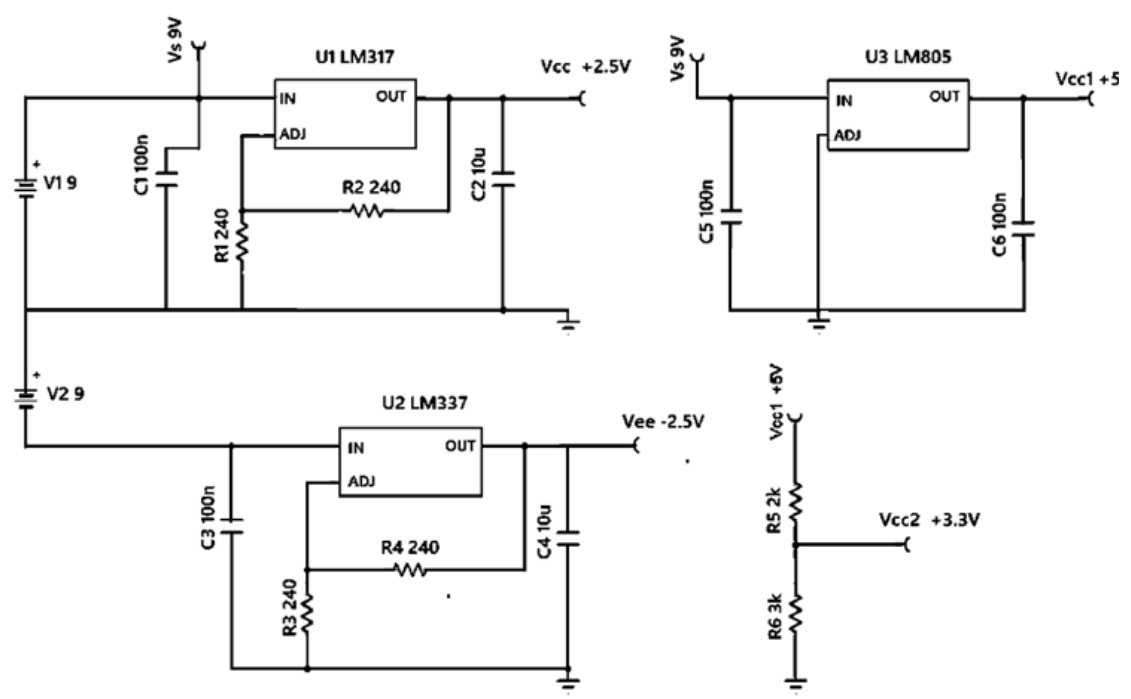

Fig. 8. Power supply management circuits for the ECG transmitting unit.

\subsection{Power management}

Figure 8 shows the power supply management circuits for transmitting unit. The AFE operates with a dual power supply of $\pm 9 \mathrm{~V}$. Voltage regulator LM317 [54] (LM337 [55]) is used to supply the $+2.5 \mathrm{~V}(-2.5 \mathrm{~V})$. Also, LM805 [56] voltage regulator is used to provide $5 \mathrm{~V}$ supply to the microcontroller. Moreover, $3.3 \mathrm{~V}$ supply is provided to the XBee transmitter through a voltage divider circuit. 
The system transmitting unit uses $6 \times$ OPA333 and $1 \times$ INA333, $1 \times$ XBee transceiver, and $1 \times$ ATmega328P. Total current for operating mode is about $53 \mathrm{~mA}$. If the whole circuit is run with a $5 \mathrm{~V}$ single supply $3000 \mathrm{mAh}$ Lithium polymer (Li-po) battery with $70 \%$ power efficiency.

A $5 \mathrm{~V}$ battery can last around 39.62 hours for continuous ECG monitoring. In certain cases, transmitting unit is not required to continuously monitor data. Battery power can therefore be saved by taking hourly short duration measurements while turning ON cyclic sleep modes. Also, reducing the ADC clock speed can further save on transmitting unit power consumption.

\section{$4 \quad$ Hardware Implementation and Testing}

Figure 9 shows the fully implemented transmitting unit using Breadboards I and II. The Breadboard I shows implementation of the AFE signal chain consisting of INA, HP filter, LP filter, non-inverting amplifier, notch filter, and voltage buffer circuits. Implementation of power management, oscillator, microcontroller, power management, and XBee circuits is shown on the Breadboard II.

A simple $16 \mathrm{MHz}$ oscillator circuit (replacing ATmega328P's internal $8 \mathrm{MHz}$ RC oscillator) is built to run the microcontroller. Voltage regulators, LM317 and LM337, are used to provide the dual power supply. A 5V Voltage regulator LM805 is used to supply the microcontroller and the XBee transmitter.

The XBee transmitter is mounted on an adapter board that has $3.3 \mathrm{~V}$ voltage regulator. Also, the voltage divider circuit is used to shift the negative AFE voltage signal to positive and then pass through the microcontroller's ADC as the input.

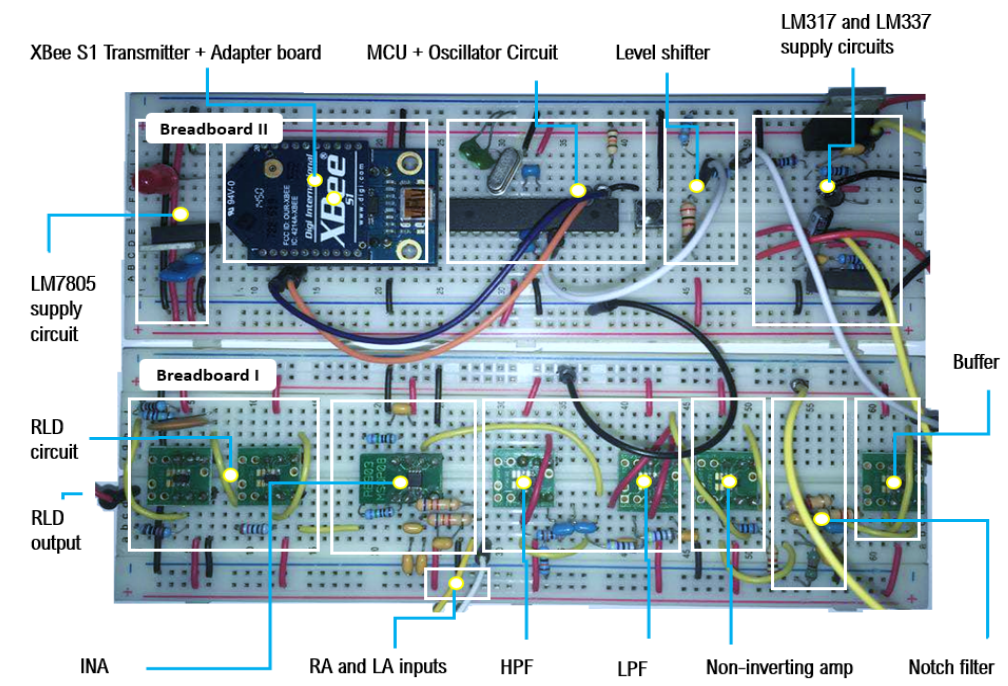

Fig. 9. Transmitting unit prototype implementation: a) Breadboard I: AFE, b) Breadboard II: microcontroller, oscillator, XBee and power management circuits. 
Experimental testing was performed in the laboratory with SKX-200 ECG simulator [57] and human generated ECG signals. A normal resting heart rate for adults range from 60 to 100 beats per minute [58]. Typically, the ECG amplitude value is in the $0.5 \mathrm{mV}$ to $1 \mathrm{mV}$ range for heart rate between 60 beats per minute and 100 beats per minute [59]. The ECG simulator was thus setup to produce a low amplitude ECG signal of $1 \mathrm{mV}$ amplitude that served as AFE input and INA was setup to have a gain of 74.52. The resulting INA output without the RLD circuit is shown in Figure 10(a). The INA output in Figure 10(a) shows a signal of $68 \mathrm{mV}$ which is lesser than the calculated value of $1 \mathrm{mV} \times 74.52=74.52 \mathrm{mV}$. In particular, the QRS complex can be seen and the INA output is shown with the DC offset introduced by the electrodes. In Figure 10(b), BP filter output is shown. The HP filter has done a good job in eliminating the DC offset. However, signal amplitude has decreased, only QR shape is noticeable in the filter output, and the signal is still noisy. The RLD circuit is then connected with the INA. The resulting INA and BPF signals are shown Fig 10(c) and 10(d), respectively. Notice that in contrast to Figure 10(a) and 10(b), relatively clean signals can be seen in Figure 10(c) and 10(d), respectively, due to the noise attenuation by the RLD circuit. There is a hint of PR and ST intervals in Figure 10 (c) and 10(d). Due to noise attenuation by the RLD circuit, a drop in the signal amplitude at INA and BPF filter outputs can be noticed as well.

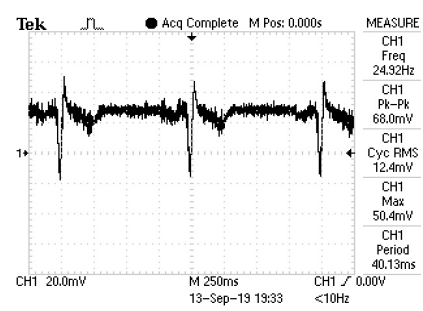

(a)

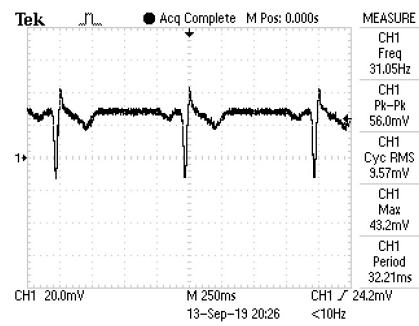

(c)

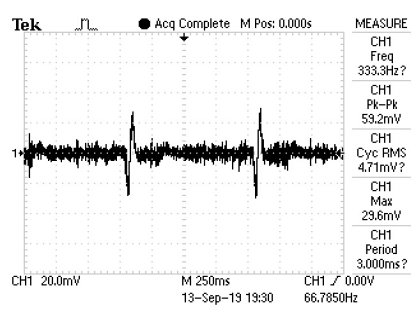

(b)

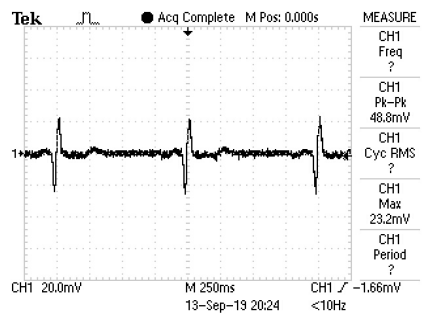

(d)

Fig. 10. a) INA output with no RLD, b) BP filter output with no RLD, c) INA output with RLD, b) BP filter output with RLD. 


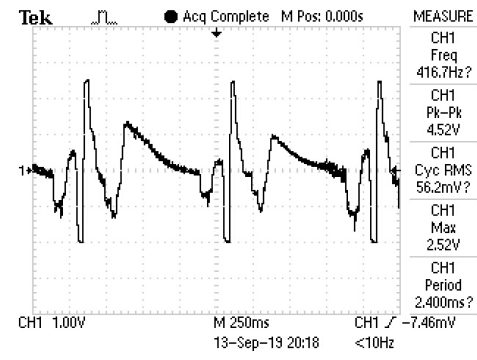

(a)

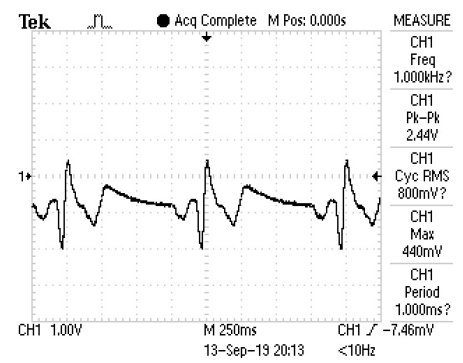

(b)

Fig. 11. a) non-inverting amplifier output b) notch filter output

Following the BP filter, a non-inverting amplifier with a gain of 101 (earlier computed gain of 11 was not adequate) is used to amplify the signal to the desired signal in the $0-5 \mathrm{~V}$ ADC input range. The amplified output is shown in Figure 11(a). The signal is still noisy but the QRS shape, PR and ST intervals are clearly visible.

For the final stage, a $50 \mathrm{~Hz}$ notch filter is used. The notch filter output is depicted in Figure 11(b). In contrast to the amplifier output signal in Figure 11(a), the notch filtered output signal has a very clear ECG shape.

The PR interval, QRS complex as well as ST interval can be clearly seen. Notice that the response of the notch circuit gradually falls away and affects frequencies on either side of the notch frequency. The negative offset and reduction in signal amplitude are thus observed in the notch filter output.

The circuit was next tested with human generated ECG signals (with RA and LA electrodes positioned on wrists and ground lead placed on the right leg). The associated results were in good match with the simulated results and overall, in both the cases prototype tests resulted in good clean ECG signals.

\section{LabVIEW Application Program}

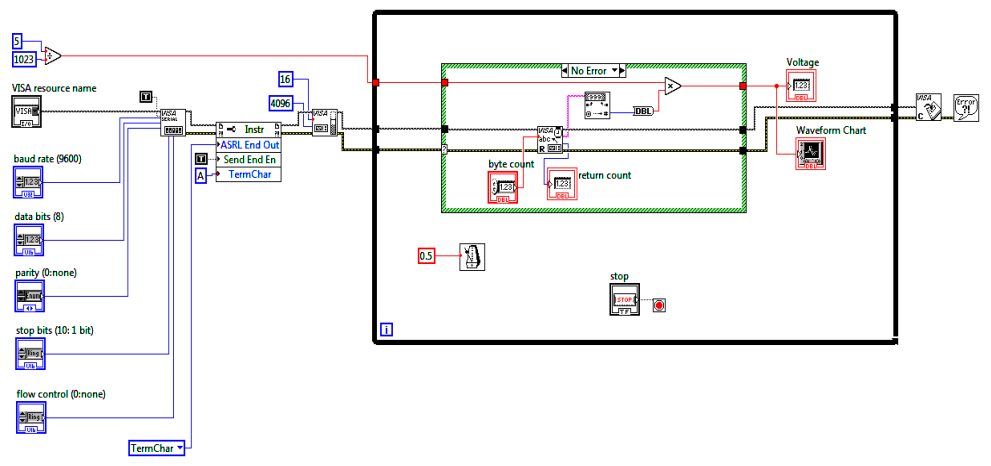

Fig. 12.Initial LabVIEW design: application program. 
LabVIEW offers a unique graphical programming-based software development environment. Graphical programs called virtual instruments (VIs) can be created by connecting terminals, constants, functions, and structures using wires on a block diagram.

A LabVIEW based application program running on the PC gateway was designed and interfaced with the XBee receiver. The key point of using LabVIEW as a software development tool for the proposed system is the ease of using NI Virtual Instrument Software Architecture (NI-VISA) [60] as a high-level API for reading data

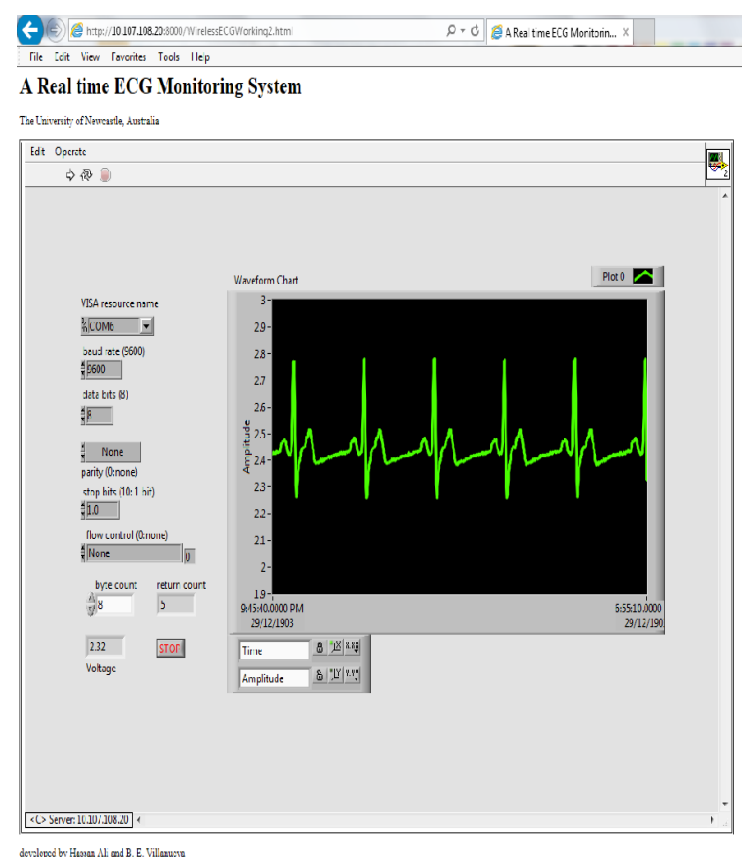

(a)

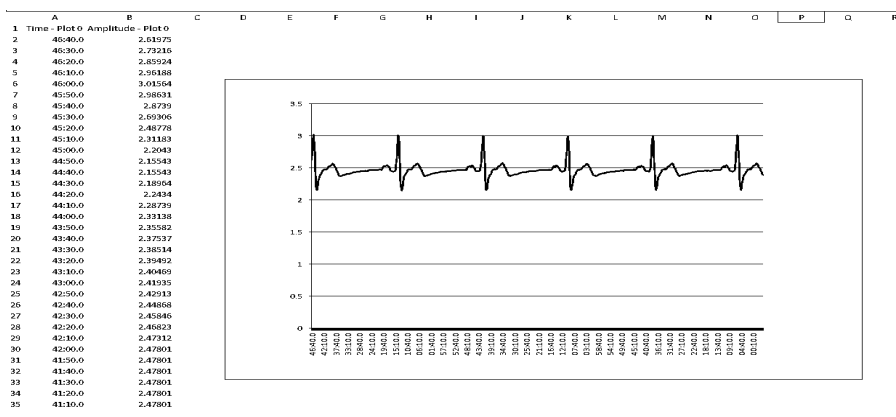

(b)

Fig. 13. Initial LabVIEW design: (a) Front panel user-interface (b) Excel recorded data. 
From PC's USB port, availability of signal processing related toolkits (Biomedical Toolkit, Advanced signal processing Toolkit, the Digital Filter Design Toolkit) and many signal processing VIs. In general, these features make it convenient for PC users to create applications, extract ECG features, and analyze ECG signals for heart rate variability analysis, cardiac arrhythmia and so on.

Figure 12 shows the NI-VISA based developed VI. The application opens a session to a give resources, does necessary configuration to the resource, performs reads to USB, closes the session to the resource and handles any errors that may have occurred. The program can run on any operating system that supports LabVIEW and NI-VISA and display the ECG signal read by XBee receiver through a waveform chart. The communication between the $\mathrm{PC}$ and $\mathrm{XBee}$ radio is through the serial port established by the PC operating system. The user thus needs to choose the COM PORT being used for the XBee receiver. User can monitor real time ECG signal through this user interface and store ECG data in Excel on the computer hard disk.

We tested ECG wireless transmission in an indoor lab environment, and it worked perfectly up to $100 \mathrm{ft}$ (30 meters). Figure 13(a) shows the captured sample result of the real time ECG data and data recorded in the Excel file is shown Figure 13(b). Note that, for the proposed system, ECG pre-processing is not required in LabVIEW as necessary preprocessing is carried out by the AFE. All relevant ECG features are clearly visible, and no $50 \mathrm{~Hz}$ noise is viewed in the signal.

\section{LabVIEW Remote Web Interface}

The web publishing tool in LabVIEW was used to develop remote interfacing for real time data monitoring, recording and control the execution of the system. The LabVIEW built-in web server was used to publish the application front panel [61]. After activating the web server, LabVIEW generated front panel that can be accessed in real time from any web browser. The browser allows connection to the same gateway PC as the server. When a remote client opens the front panel, the web server sends the front panel as front end to the client, however, the block diagram and all the VI remain on the backend gateway server PC. The system furthermore allows remote users to control the execution of system through the VI embedded in the web browser. The data acquisition still occurs on the gateway PC, nevertheless, the remote user is in full control of the application. At any point in time, the gateway PC can take control of the application from any of the remote distributed users/clients who are in control of the application.

Figure 14 (a) shows the LabVIEW web interface with patient's real time data. To view and run the published VIs remotely, the users only need to install the LabVIEW run-time engine (compatible with the version of LabVIEW on the PC gateway) for the web browser on their computers. The run-time engine includes a browser plugin package for installation in the browser plug-in directory. The LabVIEW run-time engine and relevant installer can be downloaded free of charge from the NI website.

A fully functional ECG monitoring system costing $\sim \$ 110$ is shown in Figure 14 (b). 


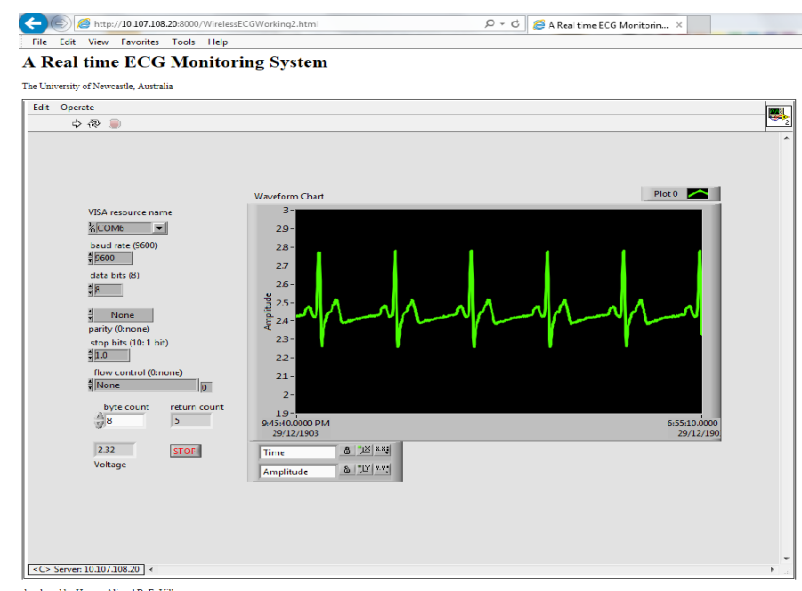

(a)

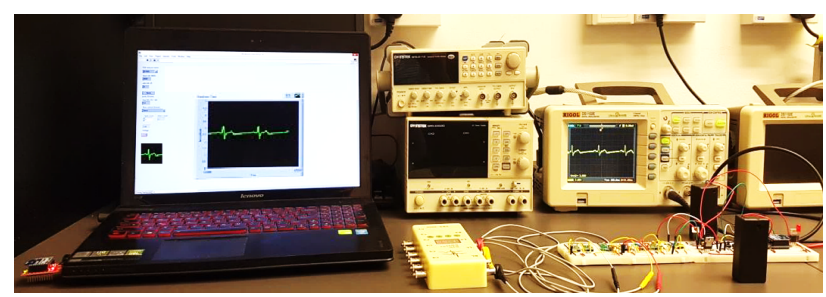

(b)

Fig. 14. (a) A VI running in LabVIEW (b) Complete ECG system prototype.

\section{Discussion}

The proposed system can wirelessly monitor a patient's ECG signals within an indoor environment (in private homes/building/hospitals) using a PC at patient's end and share the real time data through the web interface with a remote cardiologist possibly over his phone/PC/laptop. An emergency ambulance can use this system as well to share patient's ECG trace with the hospital medical staff and off-site cardiologist with the simple web access.

Presently, most of the monitoring systems use PCs to send patient's ECG data to the centralized hospital servers or public clouds from patient's home. The proposed system implements a web server on his/her PC to eliminate the need of a centralized hospital server or a cloud thereby allowing a major cost reduction. The prototype system uses proprietary hardware and software to speed up the development of the proposed ambulatory system and system results are easily reproduceable.

The hardware used to realize the development-oriented prototype costed around $\$ 110$. This low entry cost may also attract the interest of small enterprises for production-oriented design for large scale deployment. A production-oriented design 
using surface mount technology (SMT) components can significantly cut this cost to \$70-\$80, making remote ECG monitoring affordable, sustainable and effective for rural communities.

The prototype is developed using LabVIEW which involve licensing costs. However, the system can be implemented with a client-server program written in Python. The server can be implemented with the Raspberry Pi web server and the web based application /interface for the framework can be developed by using tools such as; Python, PHP web programming language, HTML, jQuery Java script framework, and MySQL database. With the pocket size, low cost and power efficient Raspberry Pi zero W [38] without display monitor (with display) replacing the PC gateway, the overall cost is expected be under $\$ 120$ (\$246).

In the current form, the proposed prototype system can be gainfully employed in biomedical electronics/instrumentation and embedded programming courses in Biomedical and Electrical/Electronic engineering undergraduate degree programs to demonstrate signal conditioning, embedded programming, wireless transmission and LabVIEW fundamentals and applications. Moreover, the proposed system can be used as a reference prototype system to build portable wireless bio and non-bio acquisition systems.

In future, the proposed transmitting unit will be miniaturized using SMT components for integration into a single printed circuit board (PCB) unit with an improved power management circuit to achieve a fully low-voltage and low-power rechargeable ECG acquisition system for wearable applications. The system will also be extended to multiple patients with a wide coverage area in a hospital setting by implementing a ZigBee wireless mesh network. The receiving unit acquired data will be further processed by employing LabVIEW based signal processing algorithms to extract ECG features, analyze cardiovascular conditions and help improve automatic diagnosis of heart diseases. Improvements in the VI design can also include, development of user data base, user selection, etc. The ECG sensors can be embedded into some wearable textiles for to minimize impact on the patient's daily activities. With the help of these improvements, long-term ECG can be monitored with ease and in a cost-effective manner.

\section{Conclusion}

A low cost prototype ambulatory wireless ECG monitoring system is designed, implemented and tested. The system deploys a low cost transmission unit at patient's end and low power Zigbee wireless communication technology between the transmitting unit and gateway PC at patient's end. A web server on the gateway PC is implemented. A client (an off-site cardiologist, clinician or medical staff in a hospital) can use the proposed system for remote monitoring of patients via a simple web access on a PC or a mobile phone.

Further software and hardware development work on the ECG transmitting unit is needed for to further reduce the cost, size and power requirements. Implementation of signal processing tools/algorithms (database) at patient's PC is also needed for im- 
proved diagnosis (for storage and retrieval of ECG traces and patient's information record). Also, transmitting unit with electrodes can be embedded in a user-friendly wearable harness or a patch for long-term ECG monitoring. It is believed that the proposed ECG monitoring system can greatly help mitigate costs associated with the deployment of remote ambulatory ECG monitoring systems for patients in rural communities.

\section{References}

[1] World Health Organization (WHO), "Cardiovascular diseases (CVDs): Key Facts" World Health Organization, Geneva. Switzerland, May 17, 2017. [Online]. Available: https://www.who.int/news-room/fact-sheets/detail/cardiovascular-diseases-(cvds) [Accessed: Sept 7, 2019].

[2] T. K. Kho, R. Besar, Y. S. Tan, K. H. Tee and K. C. Ong, "Bluetooth-enabled ECG Monitoring System," TENCON 2005 - 2005 IEEE Region 10 Conference, Melbourne, Qld., 2005, pp. 1-5. https://doi.org/10.1109/tencon.2005.300910

[3] S. Deb, S. M. R. Islam, J. RobaiatMou and M. T. Islam, "Design and implementation of low cost ECG monitoring system for the patient using smart device," 2017 International Conference on Electrical, Computer and Communication Engineering (ECCE), Cox's Bazar, 2017, pp. 774-778. https://doi.org/10.1109/ecace.2017.7913007

[4] M. A. Ahamed, M. K. Hasan and M. S. Alam, "Design and implementation of low cost ECG monitoring system for the patient using smartphone," 2015 International Conference on Electrical \& Electronic Engineering (ICEEE), Rajshahi, 2015, pp. 261-264. https://doi.org/10.1109/ceee.2015.7428272

[5] S. Majumder, L. Chen, O. Marinov, C. Chen, T. Mondal and M. J. Deen, "Noncontact wearable wireless ECG systems for long-term monitoring," in IEEE Reviews in Biomedical Engineering, vol. 11, pp. 306-321, 2018. https://doi.org/10.1109/rbme.2018.2840336

[6] K. C. Tseng, B. Lin, L. Liao, Y. Wang and Y. Wang, "Development of a wearable mobile electrocardiogram monitoring system by using novel dry foam electrodes," in IEEE Systems Journal, vol. 8, no. 3, Sept., pp. 900-906, 2014. https://doi.org/10.1109/jsyst.2013.2260620

[7] Y. Ye-Lin, J.M. Bueno-Barrachina, G. Prats-boluda, R. Rodriguez de Sanabria, J. GarciaCasado, "Wireless sensor node for non-invasive high precision electrocardiographic signal acquisition based on a multi-ring electrode," Measurement, vol. 97, pp. 195-202, 2017 https://doi.org/10.1016/j.measurement.2016.11.009

[8] E.-M. Fong and W.-Y. Chung, "Mobile cloud-computing-based healthcare service by noncontact ECG monitoring," Sensors, vol. 13, no. 12, Feb., pp. 16451-16473, 2013. https://doi.org/10.3390/s131216451

[9] B. Lin, W. Chou, H. Wang, Y. Huang and J. Pan, "Development of novel non-contact electrodes for mobile electrocardiogram monitoring system," in IEEE Journal of Translational Engineering in Health and Medicine, vol. 1, pp. 1-8, 2013.

[10] E.-M. Fong and W.-Y. Chung, "Mobile cloud-computing-based healthcare service by noncontact ECG monitoring," Sensors, vol. 13, no. 12, Fe., pp. 16451-16473, 2013. https://doi.org/10.3390/s131216451

[11] B. Jeon, J. Lee, and J. Choi, "Design and implementation of a wearable ECG system," Int. J. Smart Home, vol. 7, no. 2, pp. 61-70, 2013. 
[12] H. Xia, I. Asif, and X. Zhao, "Cloud-ECG for real time ECG monitoring and analysis," Comput. Methods Programs Biomed., vol. 110, no. 3, pp. 253-259, 2013. https://doi.org/10.1016/j.cmpb.2012.11.008

[13] H. Kwon, S. Oh, P. S. Kumar, and V. K. Varadan, "E-Bra system for women ECG measurement with GPRS communication, nano sensor, and motion artefact remove algorithm," Proc. SPIE 8548, Nano systems in Engineering and Medicine, no. 8548, 2012, pp. 1-9. https://doi.org/10.1117/12.946121

[14] AliveCor "Peace of mind". [Online]. Available: https://www.alivecor.com/?gclid=EAIaIQobChMI8u2iz_fw1gIVEIJpCh2HOwkTEAAYA SABEgLdv_D_BwE[Accessed: Sept 7, 2019].

[15] Qardio "Smart wearable ECG EKG monitor-QardioCore". [Online]. Available: https://www.getqardio.com/qardiocore-wearable-ecgekg-monitor-iphone/. [Accessed: Sept 7, 2019].

[16] Lohman Technol "AFibAlert-Heart rhythm monitor with instant atrial fibrillation detection", Lohman Technologies. [Online]. Available: http://www.lohmantech.com/. [Accessed: Sept 7, 2019].

[17] GIMA “CARDIO-B PALM ECG," Gima S.p.A. Via Marconi, Italy. [Online]. Available: http://www.gimaitaly.com/prodotti.asp?sku=33261\&dept selected=580\&dept $\mathrm{id}=5800$. [Accessed: Sept 7, 2019].

[18] Cardiocomm, "The HeartCheck PEN handheld ECG device," CardioComm Solutions Inc., North York, ON, Canada. [Online]. Available: http://www.cardiocom msolutions.com/QTStudy/[Accessed: Sept 7, 2019].

[19] The HeartCheck. "PHYSICIANS," [Online]. Available: http://www.theheartcheck.com/physician.html. [Accessed: Sept 7, 2019].

[20] Cardiac Designs "Easy ECG Check," Cardiac Designs Inc., San Francisco, CA USA [Online]. Available: http://cardiacdesigns.com/. [Accessed: Sept 7, 2019].

[21] Dimetek "Color portable ECG recorder dicare m1CC," Dimetek Digital Medical Technologies, Ltd. [Online]. Available: http://www.dimetekus.com/Color-Portable-ECGRecorder-Dicare-m1CC p234.html. [Accessed: Sept 7, 2019].

[22] Heal Force "Easy ECG Monitor-PC-80A (Bluetooth 4.0)," Heal Force Biomeditech Holdings Limited. [Online]. Available: http://www.healforce.com/en/index.p hp? ac=article\&at=read\&did=176. [Accessed: Sept 7, 2019].

[23] "CardioSecur: Mobile ECG with 12 or 22 leads", Personal MedSystems GmbH. [Online]. Available: https://mobile-ecg.com/. [Accessed: Sept 7, 2019].

[24] AliveCor "Peace of mind". [Online]. Available: https://www.alivecor.com/?g clid=EAIaIQobChMI8u2iz_fw1gIVEIJpCh2HOwkTEAAYASABEgLdv_D_BwE. [Accessed: Sept 7]

[25] M. Marouf, G. Vukomanovic, L. Saranovac, M. Bozic, "Multi-purpose ECG telemetry system," BioMed Eng OnLine, vol.16, no. 80, 2017. https://doi.org/10.1186/s12938-017$\underline{0371-6}$

[26] X. Sun and Y. Zhang, "Design and Implementation of Portable ECG and Body Temperature Monitor," 2014 International Symposium on Computer, Consumer and Control, Taichung, 2014, pp. 910-913. https://doi.org/10.1109/is3c.2014.239

[27] C. Lin et al., "An Intelligent Telecardiology System Using a Wearable and Wireless ECG to Detect Atrial Fibrillation," IEEE Transactions on Information Technology in Biomedicine, vol. 14, no. 3, pp. 726-733, May 2010.

[28] M. Raileanu, S. Busnatu, C. Sinescu, "The Implications of Cardiovascular Home Monitoring Rehabilitation - Mobile Applications as Optimum Solutions for the Future," Interna- 
tional Journal of Online and Biomedical Engineering, vol. 11, no. 5, pp. 38-42, 2015. https://doi.org/10.3991/ijoe.v11i5.4864

[29] H. Kobayashi, "Intelligent wireless EMG/ECG electrode employing ZigBee technology," SICE Annual Conference 2011, Tokyo, 2011, pp. 2856-2861.

[30] J. Güttler and T. Bock, "Developing a low-cost capacitive ECG via Arduino and single board computer interfaced with capacitive electrodes for prevention and security aspects," 34th International Symposium on Automation and Robotics in Construction (ISARC), July 2017. https://doi.org/10.22260/isarc2017/0011

[31] A. Muankid, M. Ketcham, "The Real-time Electrocardiogram Signal Monitoring System in Wireless Sensor Network," International Journal of Online and Biomedical Engineering, vol. 15, no. 2, pp. 4-19, 2015. https://doi.org/10.3991/ijoe.v15i02.9422

[32] X. Zhang, Y. Zhao, W. Zhao, Wei-wei Xu, Wen-chao Ji, "A Wireless Sensor Networksbased Intelligent System for Library Air Quality Monitoring," International Journal of Online and Biomedical Engineering, vol. 12, no. 10, pp.76-79,2016. https://doi.org/10.39 91/ijoe.v12i11.6227

[33] Technopedia, ZigBee Available: https://www.techopedia.com/definition/4390/zigbee

[34] N. Dey, A. S. Ashour, F. Shi, S. J. Fong and R. S. Sherratt, "Developing residential wireless sensor networks for ECG healthcare monitoring," IEEE Transactions on Consumer Electronics, vol. 63, no. 4, Nov., pp. 442-449, 2017. https://doi.org/10.1 109/tce.2017.015063

[35] Onder Yakut, Serdar Solak, Emine Dogru Bolat "Implementation of a web-based wireless ECG measuring and recording system" International Journal of Electrical, Computer, Energetic, Electronic and Communication Engineering, vol. 9, no. 10, pp. 815-818, 2015.

[36] L. V. R. Kumari, N. Balaji, Y. P. Sai and K. T. Kumar, "ECG monitoring system using ARM9 web-server," 2015 Global Conference on Communication Technologies (GCCT), Thuckalay, 2015, pp. 234-237. https://doi.org/10.1109/gcct.2015.7342658

[37] H. Ozkan, O. Ozhan, Y. Karadana, M. Gulcu, S. Macit and F. Husain, "A Portable Wearable Tele-ECG Monitoring System," in IEEE Transactions on Instrumentation and Measurement. https://doi.org/10.1109/tim.2019.2895484

[38] Raspberry Pi Foundation, "Raspberry Pi Zero W" [Online]. Available: https://www.raspberrypi.org/products/raspberry-pi-zero-w/. [Accessed: Oct 10, 2019]. https://doi.org/10.1002/9781119211051.ch8

[39] National Instruments, "What is LabVIEW?,". [Online]. Available: https://www.ni.com/ensg/shop/labview.html. [Accessed: Sept 7, 2019].

[40] SparkFun, "SparkFun Xbee explorer dongle" [Online]. Available: https://www.sparkfun.com/products/11697. [Accessed: Sept 7, 2019].

[41] Texas Instruments, "OPAx333 1.8-V, micro power, CMOS operational amplifiers, zerodrift series," OPA333 datasheet, March 2006, [Revised Dec. 2015].

[42] C. Kitchin, and L. Counts, A Designer's Guide to Instrumentation Amplifiers, $3^{\text {rd }}$ ed., Ana$\log$ Devices, Inc. USA, 2006. [Online]. Available: https://www.analog.com/media /en/training-seminars/design-handbooks/designers-guide-instrument-amps-complete.pdf. [Accessed: Oct 13, 2019]

[43] Texas Instruments, "INA333 micro-power $(50 \mu \mathrm{A})$, zerø-drift, rail-to-rail out instrumentation amplifier," INA333 datasheet, Jul. 2008 [Revised Dec. 2015].

[44] Texas Instruments, "INA12x precision, low-power instrumentation amplifiers," INA128 datasheet, Oct. 1995 [Revised Apr. 2019].

[45] Texas Instruments, "INA118 Precision, low power instrumentation amplifier," INA118 datasheet, Sept. 2000 [Revised Apr. 2019]. 
[46] F. Parola and J. Garcia-Niebla, "Use of High-Pass and Low-Pass Electrocardiographic Filters in an International Cardiological Community and Possible Clinical Effects," Adv $J$ Vasc Med., Vol. 2, no. 1, pages 034-038, 2017.

[47] Ching-Sung Wang, "A new AC-coupled amplifier for portable ECG without reference electrode," Computers \& Electrical Engineering, vol. 39, np. 1, pp. 141-149, 2013. https://doi.org/10.1016/j.compeleceng.2012.07.011

[48] E. M. Spinelli, R. Pallas-Areny and M. A. Mayosky, "AC-coupled front-end for biopotential measurements," in IEEE Transactions on Biomedical Engineering, vol. 50, no. 3, March, pp. 391-395, 2003. https://doi.org/10.1109/tbme.2003.808826

[49] Mocrochip, “ATmega48A/PA/88A/PA/168A/PA/328/PAtmega328P," megaAVR® Data Sheet, 2018. [Online], Available: http://ww1.microchip.com/downloads/en/D eviceDoc/ATmega48A-PA-88A-PA-168A-PA-328-P-DS-DS40002061A.pdf. [Assessed Oct. 11, 2019] https://doi.org/10.4016/32859.01

[50] Digi International Inc, "Digi XBee ${ }^{\circledR}$ Family Features Comparison”, XBee family comparison-1995-2017. [Online]. Available: https://www.digi.com/pdf/chart_xbee_rf_features.pdf. [Accessed: Oct 8, 2019]

[51] Digi International Inc, "XBee ${ }^{2} / X B e e-P R O \circledR ~ R F$ Modules”, XBee data sheet, Sept 2009. [Online]. Available: https:/www.sparkfun.com/datasheets/Wireless/Zigbee/XBeeDatasheet.pdf. [Accessed: Sept 7, 2019]. https://doi.org/10.1016/b978-0-12-391404$\underline{0.00032-6}$

[52] "XBee breadboard adapter" [Online]. Available: https://www.amazon.com/SparkFunXBee-Breadboard-Adapter/dp/B077DRMP5Z. [Accessed: Sept 7, 2019].

[53] Digi, "X-CTU software", [Online]. Available: https://www.digi.com/su pport/productdetail?pid=3352. [Accessed: Sept 7, 2019].

[54] Texas Instruments, "LM117, LM317-N wide temperature three-pin adjustable regulator,"LM317 datasheet [Online]. Available: http://www.ti.com/lit/ds/symlink/lm117.pdf [Accessed: Sept 7, 2019].

[55] Texas Instruments, "LM137, LM337-N 3-Terminal adjustable negative regulators", LM337 datasheet. [Online]. Available: http://www.ti.com/lit/ds/symlink/lm137.pdf [Accessed: Sept 7, 2019].

[56] Texas Instruments, " $\mu \mathrm{A} 7800$ series positive-voltage regulators,"LM7805 data sheet. [Online]. Available: https://www.sparkfun.com/datasheets/Components/LM7805.pdf. [Accessed: Sept 7, 2019].

[57] "SKX-2000C ECG simulator ECG signal simulator ECG generator". [Online] Available: https://www.aliexpress.com/item/32810011459.html. [Accessed: Sept 7, 2019].

[58] E. Louisville, "Ask Well: How Do You Use a Heart Rate Monitor?," in Blog, Caregiver Education, Exercise, Exercise/Keeping Fit (August 18, 2014). [Online]. Available: http://www.eldercareresourceslouisville.com/ask-well-how-do-you-use-a-heart-ratemonitor/. [Accessed: Sept 13, 2019].

[59] Kah-Meng Chew and D. Lau, "ECG Small Signal General and Analysis," Tech Briefs (Dec 1, 2016). [Online]. Available: https://www.techbriefs.com/component/cont ent/article/tb/supplements/tmtb/features/articles/26085. [Accessed: Sept 13, 2019].

[60] National Instruments "NI-VISA overview". [Online]. Available: http://www.ni.com/pro duct-documentation/3702/en/. [Accessed: Sept 7, 2019].

[61] N. Shenkeshi, M. Fortenberry, Y. Kawachi, and C. Yapura, "Remote Panels in LabVIEW - Distributed Application Development", LabVIEW (Nov 20, 2018) [Online]. Available: http://ww.ni.com/tutorial/4791/en/. [Accessed: July 13, 2019]. 


\section{Authors}

Hassan Ali earned his PhD from the University of Melbourne, Australia (2003). $\mathrm{He}$ is a Conjoint Senior Lecturer with the School of Electrical Engineering and Computing at the University of Newcastle (UON), NSW 2308, Australia. Hassan has research interests in embedded systems, mobile communications, sensor networks, Internet of Things, smart grid, and smart cities. He is Senior Member of the Institute of Electrical and Electronics Engineers (IEEE), USA. hassan.ali@newcastle.edu.au

Ben Ernest Villanueva received his undergraduate degree in electrical engineering from the University of Newcastle, Australia. He is a Hardware Development Engineer at Rockwell Automation Southeast Asia, Corporation Place, Singapore 618494. Ben has research interests in hardware and software technologies. Befv28@gmail.com

Raziq Yaqub received his PhD from the Keio University, Japan (1997), a master's degree in electrical engineering from the University of Engineering and Technology (UET), Peshawar, Pakistan (1993), and an MBA degree in Marketing from Fairleigh Dickinson University, NJ, USA. Raziq is an Associate Professor in the Department of Electrical Engineering and Computer Science at Alabama A\&M University, Normal, Alabama 35762, USA. He has research interests in mobile communications, biomedical electronics, cybersecurity, smart Grid, and EVs. Also, Raziq is Senior Member of the IEEE, USA and has been actively contributing to Technical Committees of interna-tional conferences and as well as a reviewer for several reputed engineering journals. Raziq.yaqub@aamu.edu

Article submitted 2019-08-14. Resubmitted 2019-09-28. Final acceptance 2019-10-17. Final version published as submitted by the authors. 